\title{
Music and Social Skills for Young Children with Autism: A Survey of Early Childhood Educators
}

\author{
Anna ARCHONTOPOULOU ${ }^{1}$, Potheini VAIOULI²
}

\begin{tabular}{l} 
AR T ICLE INFO \\
\hline Article History: \\
Received 17.11.2019 \\
Received in revised form \\
01.05 .2020 \\
Accepted \\
Available online \\
01.07 .2020
\end{tabular}

\begin{abstract}
Children with autism may have difficulties in communicating with others, developing social relationships and maintaining emotional reciprocity. Children's active involvement with musical activities may create the conditions for enhanced moments of learning and communication and it may promote children's sensory-motor abilities and their cognitive and emotional skills. The aim of this study was to investigate the views of early childhood educators on the use of music as a tool for enhancing students' with autism social skills. Participants were 94 early childhood educators, working at Greek public schools. The results were positive regarding the participants' views on the use of music as an important, instructional tool in the classroom that holds the potential to promote social and emotional growth of young children with autism. Implication of the study pinpoint to additional research on the topic and to professional development of early childhood educators on the use of music.
\end{abstract}

(C) IJERE. All rights reserved

Keywords: ${ }^{1}$

Autism, Music, Social Relationships, Emotional Development, Early Childhood Educators.

\section{INTRODUCTION}

Young children are social beings from birth. They want and need social interactions and these interactions set the stage for social development and learning (Missall \& Hojnoski, 2008; Stern, 1985). Specifically, during the first 12 months of an infant's life early stimulations from the environment are of critical importance: they promote brain changes, the formation of neural connections, and patterns of change and growth (Kagan \& Herschkowitz, 2005; Johnson, 2000; Bransford, Brown, \& Cocking 1999; Shonkoff \& Philips, 2000). Eventually, the interplay between the growing child and her experiences in her social environment is what defines the child's development (Plomin, 1994; Shonkoff \& Phillips, 2000).

Social development and learning continue as young children move from their family environment to early childhood settings. Diverse engaging and age-appropriate activities, guided participation, organized by their teachers, the interactions with other peers and adults in the room set the stage for a number of social and developmental outcomes that in time outline young children's overall growth (Odom, McConnell, and Brown, 2008). Such learning episodes are further enhanced with activities embedded within the contexts of natural setting and ongoing playing (Ridley, McWilliam \& Oates, 2000) that present multiple opportunities for arousing children's attention, curiosity, and motivation, and for addressing a range of interests, preferences, and personal learning styles (Horn \& Banerjee, 2009). This is important because engaging teaching moments, embedded in the children's natural environment, allow for learning to evolve as an integral part of the children's culture, routines, and actions in their school setting (Powell, Burchinal, File, Kontos, 2008; McWilliam \& Casey, 2008).

Although this may happen effortlessly to most children, young children with Autism Spectrum Disorder (ASD) seem to miss the opportunity to benefit from engaging learning episodes in the classroom because of challenges with social interactions and reciprocal social communication. ASD is a lifelong neurodevelopmental disorder characterized by challenges in social communication as well as by restrictive and repetitive patterns of behaviors, interests, and activities (American Psychiatric Association, 2013). Challenges in reciprocal communication usually impact language acquisition and further deprive young children with autism of learning new skills through interacting with people in their environment (Mundy \& Neal, 2001). As such, offering contexts for learning that are engaging and promote the interplay between

Corresponding e-mail: archontopoulou.anna@hotmail.com, European University Cyprus ,orcid.org/0000-0002-0780-4621

University of Cyprus, orcid.org/0000-0002-6651-8633 
children and their social environment are of critical importance for young children with ASD in early childhood settings.

Music activities embedded in early childhood programs is a promising method for supporting social and academic growth for all learners, including those with ASD (McDowell, 2010). Music is inherent to children's experiences and serves as a scaffold that fosters children's participation at their level of abilities and encourages self-expression (Anvari, Trainor, Woodside, \& Levy, 2002). Campbell (2010) conducted an ethnographic study that indicated that music plays a pivotal role in children's life and can offer the context for socialization and communication among young children, their peers, and their parents. During their interactions with the researcher, young children indicated that songs and music is their way of exploring the word and making connections with important life events, for making friends, and for relating with their family members. Campbell (2010) concluded by describing music actions at the first years of a child's life as the context for the development of inter-subjectivity, communication, and intentionality among young children.

Descriptions of music interventions define music experience as the playful context that encourages the child to be in a dialectical relationship with everyone participating in the music-making process. Musical interactions can be a multi-faceted activity that fosters young children's affective and interpersonal engagement with other adults and peers in their social environments (Welch \& McPherson, 2012; Ockelford, 2012; Kim et al. 2008; Kern \& Aldridge, 2006). For example, research shows that children with global developmental delays and minimum language skills may participate in reciprocal, musical interactions during music therapy improvisation episodes (Ockelford, 2011a; Ockelford \& Matawa, 2010; Vaiouli \& Andreou, 2017). Music techniques and music therapy interventions have been implemented as the social context for promoting communication, interactions, and joint experiences among children with ASD and others in their social environment (i.e. Simpson \& Keen, 2011; Tarrant, North \& Hangreaves, 2000). Other studies explored the use of specific music components, such a songs, music and movement, to enhance socio-communicative responsiveness for young children with autism (Geretsegger et al., 2014; Vaiouli et al, 2015; Duffy \& Fuller, 2000; Finnigan \& Star, 2010; Lim, 2010; Wan et al., 2011; Simpson et al., 2013).

Within school settings, music has been embedded into classroom routines as the context to promote engagement and participation during social interactions of the participants (Kern \& Aldridge, 2006; Kim et al., 2008; Stephens, 2008). Findings pinpoint to aspects of music-making that enhance the inclusion of children's interests in the intervention, allow for peer interaction, and promote the development of social engagement as an additional outcome of participating in music-making. That is, while young children participate in music-making actions, they use their emerging understanding of others' intentions in order to interact musically and socially with other communicative partners. As such, using music activities as an instructional tool in the classroom may hold the potential to promote engagement and intensify learning of all children while specifically addressing the needs of young with ASD (Vaiouli \& Ogle, 2015; Vaiouli \& Friesen, 2016).

\section{Aim of the Study}

Overall, music is a well-established tool in promoting engagement and learning for all children, including children with autism in early childhood settings. However, there is limited evidence on the perceptions of early childhood educators on the use of music in their classrooms, possible challenges they face, and their everyday practices in relation to music. On the other hand, there is evidence on the challenges early childhood educators may have when implementing music in their classrooms. Specifically, current studies have shown that Greek early childhood educators seem to have limited knowledge on the use of music as a teaching tool in their classrooms and they may end up feeling unprepared or insecure when implementing music in the school's daily routines (Chrysostomou et al., 2007; Koutsoupidou, 2010). Similarly, studies that investigated Greek and Cypriot pre-service teachers' academic music training in relation to their levels of confidence for teaching music in their classrooms, reported that pre-service teachers lack practical experience and adequate preparation in teaching music, which may affect their levels of selfefficacy, enthusiasm, and creativity for implementing music activities in their classrooms (EconomidouStavrou, 2013; Koutsoupidou, 2010). 
Teacher's self-efficacy beliefs play a critical role in providing quality instruction and in implementing new practices for all students in their classrooms (Hudson \& Hudson, 2007). Recognizing the dialectical role between knowledge, experience, and teaching practices, the aim of this study was to explore the perceptions of Greek, in-service, early childhood educators (ECE) on the use of music as a tool to promote social and emotional development of young children with ASD in inclusive early childhood settings. Specifically, the researchers sought to evaluate (a) ECE's knowledge and experiences when using music as an instructional strategy in the classroom, (b) ECE's perceptions and understanding regarding the efficacy of such strategies, and (c) the main music strategies implemented by ECE in their classrooms to promote young children's with ASD emotional and social development.

\section{METHOD}

\section{Participants and Instrument}

According to the Greek Ministry of Education, children included in schools exhibit deficits in areas of communication, emotion recognition and expression, and social interaction. Specifically, they have minimum speech, lower verbal reasoning ability and high functioning (European Agency for Development in Special Needs, 2012). Children with special needs in primary and secondary schools are mainly served in resource room settings $(73.17 \%)$, attend special schools $(21.83 \%)$, or they included in general classrooms $(5 \%)$. However, there is lack of descriptive data in regards to children with disabilities in early childhood settings. A recent study by Fyssa \& Vlachou (2015) investigated the quality of inclusive education in Greek early childhood setting and they reported that $38.40 \%$ of the children were diagnosed with autism spectrum disorders in their sample, with no further information on the functioning level of the participants. As such, we have limited information on the number of children on the spectrum these educators are interacting with in Greek public schools.

In this study, 150 preschool teachers drawn from different geographical regions from Northern (Chalkidiki, Katerini, Kavala, Kilkis, Naousa, Serres, Thessaloniki, Veria) Central (Athens) and Southern (Chania) parts of Greece were contacted to participate in the study. The participating teaches were selected randomly from a list of preschool inclusive settings provided by the Educational Board Directories in each city. Criteria for contacting the teachers were the following: (a) participants were working in inclusive public preschool settings at the time of the study, (b) participants were serving children aged 4 to 6 years old, (c) participants served children with ASD in their classrooms. Total of 94 teachers responded to the questionnaire. The age range was $22-55$ and both sexes were represented in the sample with $26.6 \%$ of them being male and $73.4 \%$ being female. The age range of the participants was 22-55 (mean 2, 0745) and years of experienced from 0 to $10+$ years. Most of the participants were serving in inclusive early childhood settings that included students with ASD (72.2\%) while only $27.7 \%$ were teaching in special education classrooms. Finally, only $7.4 \%$ of the participants reported that they have formal music education (that is a Bachelor's degree in music) and 30.9\% reported that they have a certification in music from attending short trainings (equivalent to 10-20 hours of professional development) although all of them are required to teach music in their respective settings. Table 1 displays the demographic information of the participants.

Invitations to participate in the study were sent in two different phases. First, teachers were contacted electronically through the Educational board directories in each city. This first call for participants to the study led to a $45 \%$ response rate (around 40 responders). To enhance the response rate, the same schools were contacted two weeks later via email and through social databases (the school's page on facebook where it was available). During the same period, the invitation was extended via personal communication between the first author and the school principals of schools in the targeted areas. 
Table 1. Demographic information of the participants ( $\mathrm{N}=94)$

\begin{tabular}{|c|c|c|c|c|}
\hline \multicolumn{3}{|c|}{ Variables } & $\mathrm{N}$ & $\%$ \\
\hline \multirow{2}{*}{\multicolumn{2}{|c|}{ Gender }} & Female & 69 & 73,4 \\
\hline & & Male & 25 & 26,6 \\
\hline \multirow{2}{*}{\multicolumn{2}{|c|}{ Level of Education }} & Bachelor & 86 & 91,5 \\
\hline & & Master & 8 & 8,5 \\
\hline \multirow{3}{*}{\multicolumn{2}{|c|}{ Qualification in Music Education }} & No formal qualification & 87 & 92,6 \\
\hline & & Bachelor's Degree & 7 & 7,4 \\
\hline & & Certificate of music & 29 & 30.9 \\
\hline \multirow{6}{*}{$\begin{array}{l}\text { Teaching } \\
\text { Experience }\end{array}$} & & $0-5$ years & 22 & 23,4 \\
\hline & Years of Teaching & 6-10 years & 19 & 20,2 \\
\hline & Experience & $11-15$ years & 35 & 37,2 \\
\hline & & More than 15 years & 18 & 19,2 \\
\hline & \multirow[b]{2}{*}{ Current position } & Classroom teacher in special school & 26 & 27,7 \\
\hline & & Classroom teacher in regular school & 68 & 72,3 \\
\hline
\end{tabular}

\section{Instrument Design}

An online questionnaire was developed by the investigators based on current knowledge on ECE, research on music, music therapy and autism, and relevant practices in Greek public inclusive preschools. The questionnaire in total included 30 questions of which 21 were Likert-Scale type of questions (the responses ranged from 1-5, with $1=$ strongly disagree and $5=$ strongly agree) and 3 open-ended questions to allow for a deeper understanding of the beliefs and practices of the participants on the use of music in their classrooms. Appendix A includes the whole questionnaire. All questions were divided into four sections:

A) The demographics of the respondents.

B) The teachers' perceptions on the effectiveness of various music strategies to promote students' emotional development.

C) The teachers' perceptions on the effectiveness of various music strategies to promote students' social development, and

D) Types of music activities implemented by the participants in their classrooms.

An expert in music therapy and early childhood special education (involved in ASD and research) reviewed draft of the questionnaire and provided suggestions to strengthen the content and structure of the instrument. The questionnaire was piloted with 18 teachers at the beginning of the study and two questions were eliminated based on the feedback of the participants in the pilot study. In addition, certain questions were re-phrased for clarity, according to the respondents' comments. Some respondents suggested changes to the layout of the questionnaire in order to make it more concise and attractive. According to these proposals, the appropriate modifications were made in order to obtain a clear, reliable and respondentfriendly questionnaire.

In its final form, the first section of the questionnaire included demographic information of the participants. In the second section, which encompassed 13 questions regarding students with ASD and their emotional development, participants were asked to assess the use of music activities as a tool to promote emotional development for young children with ASD. The questions focused on the participants' beliefs on using music activities to gain insight on children's with ASD emotional state as well as on the use of music as a way to promote self-expression and to provide an emotional outlet for anxiety and stressful emotions (for example, whether musical behaviors may reflect children's emotional states). This section included 
questions about music free play among children and adults in the classroom as a tool for tension-release experiences.

The third section of the questionnaire included 8 questions. The focus was on music activities to enhance socialization, specifically exploring the participants' views on the use of music as an educational tool that may promote positive peer relationships in the classroom and support young children with ASD when following classroom rules and routines. Certain questions focused on the use of music during the school day (including instructional time, free play, and recess) as a way to create a classroom culture that promotes peer and adult interactions and the sense of belonging for all children in the room. For example, one such question asked participants to rate from 1-5 whether participation in shared singing may promote a sense of belonging.

The final section that included 4 questions in total, asked participants about the use of specific music activities embedded in their usual teaching routines. This part of the questionnaire included common, music education strategies that are typically implemented in early childhood settings. Some examples included singing, listening and moving to music, and playing certain musical instruments. The participants were invited to rate their levels of familiarity with certain music education approaches such as the Orff approach and the Kodaly and Suzuki methods and they were asked to describe how they implemented music activities in their classrooms, and finally, how they made decisions on the use of music based on the needs of children with ASD. These questions were included in the questionnaire in order to investigate if the respondents were aware of certain music approaches theoretically and practically and if they combined their general knowledge about these approaches with their own activities, which were implemented in the classrooms.

\section{Data Analyses Data Collection Procedures}

Prior to the data collection, the Research Ethics Committee reviewed and granted approval of the study. A letter addressed to the Educational Board of each city, an email message, and social postings informed potential participants of the goals, the purpose, and the nature of the study. Interested teachers were instructed to follow the hyperlink of the online survey uploaded in the Google-Form platform. The complete questionnaire, translated in English, can be found in Appendix A.

Participation in the study was voluntary and anonymous. There were sent two reminders to all participants for the completion of the questionnaire. For the participants who were given hard copies, they were instructed to complete them within a week and return them to the investigators. Data was collected for a total of 12 weeks. All completed questionnaires were then gathered and analyzed by the first author.

\section{Data Analyses}

All completed questionnaires were gathered for data analysis through the SPSSV20 Software. The use of this program enabled the presentation of results in percentages, tables, and charts. Table 2 shows the means and standard deviation (SD) of the participants' responses. The open-ended questions were analyzed by following an open-coding procedure: (a) Read the data as a whole to approach the content of the responses, (b) Develop codes based on the exact wording and units of the respondents, (c) Sort the codes into emerging themes, and (d) provide a summary of the data. Overall, the open-ended questions were answered by $75.5 \%$ of the respondents, while $24.5 \%$ chose not to respond. 
Table 2. Means and Standard Deviations from each section in the Questionnaire

\begin{tabular}{llll}
\hline Category & Sub-theme description & M & SD \\
\hline Emotional Development & Communication & 4,0213 & 0,71810 \\
& Sense of Security & 4,0319 & 0,72516 \\
& Communication through music & 3,8723 & 0,83259 \\
& Emotional state and music & 4,000 & 0,77598 \\
& Expression of positive and negative & 3,9894 & 0,87369 \\
& feelings & \\
& Containment of positive and negative & 3,4894 & 1,00263 \\
& feelings & & \\
& Externalize anxiety & 3,7340 & 0,94101 \\
Social relationships & 4,0000 & 0,84242 \\
& Teaching rules and routines & 3,8936 & 0,86096 \\
& Connectedness with others & 3,9681 & 0,86076 \\
& A sense of belonging in group & 3,8617 & 0,92284 \\
& Solidarity & 3,9362 & 0,82708 \\
& Reaction to others & 3,9787 & 0,85482
\end{tabular}

\section{FINDINGS}

Descriptive analysis of the questionnaire was first carried out using the frequency data for each variable. The results are presented in groups relevant to the three parts of the questionnaire: (a) Music as a tool for emotional development and self-expression, (b) Music as a tool for social development, and (c) Music strategies implemented in the classroom.

\section{Music as a Tool for Emotional Development and Self-expression}

The participants were positive on the use of music as the context for enhancing students' with ASD emotional development. Looking at specific items of this part of the questionnaire, $48.9 \%$ agreed and $26.6 \%$ strongly disagreed that music holds the potential to create a safe and predictive environment for students' with ASD emotional development. Similarly, 51.1\% agreed that music is an outlet for students' expression and creativity.

$42.6 \%$ of the participants agreed with the statement that specific characteristics of music (such as rhythmical patterns, happy or sad melodies, and different dynamics) help them assess their students' with ASD emotional state and needs. When asked about certain aspects of children's with ASD emotional development, $37.2 \%$ of the respondents agreed that music activities in the classroom can be used as a tool to promote children with ASD self-esteem and $36.2 \%$ agreed that music is an outlet for expressing negative emotions. In regards to emotional development, $45.7 \%$ of the participants agreed that music can support emotional management for students with ASD and 37.2\% agreed that music-making in groups may support children express a range of emotions (extending from negative emotions to positive ones) in an appropriate manner. Figure 1 illustrates visually the participants' responses on the use of music to enhance emotional development of young children with ASD in their classrooms. 
Figure 1.Participants' responses on the effectiveness of music on emotional development and selfexpression

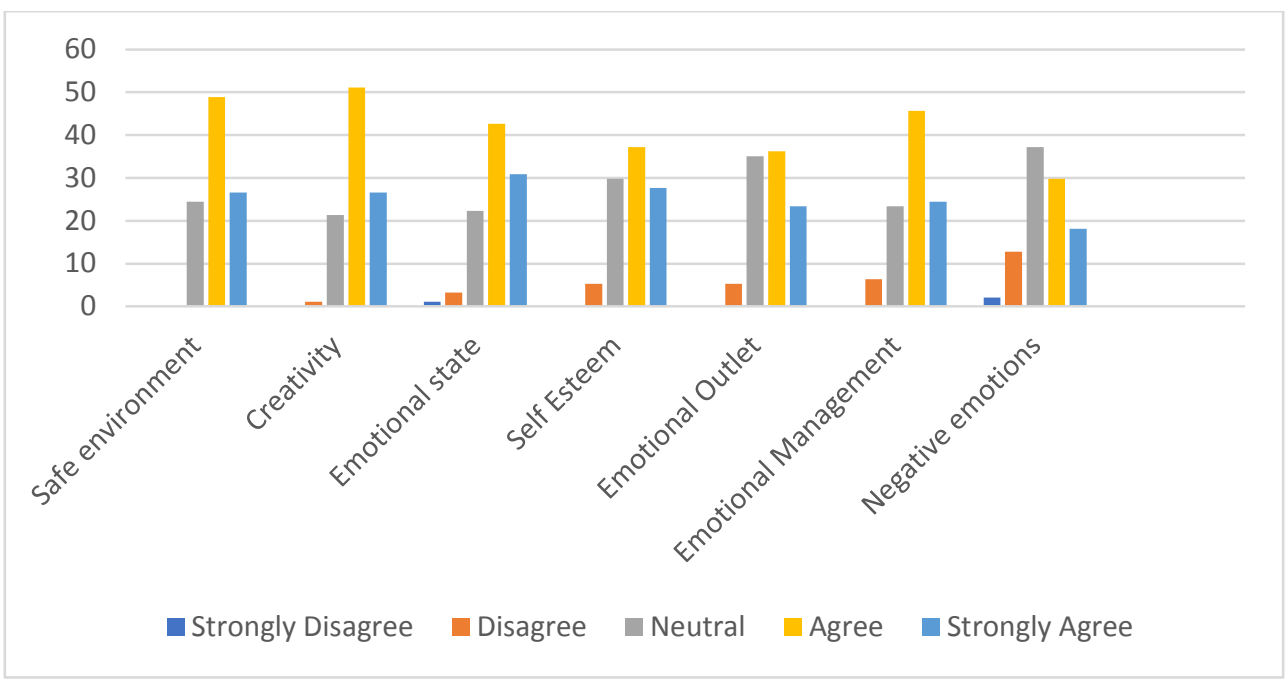

Although the respondents seem to identify music as a helpful tool for promoting a variety of emotional outcomes it is interesting to identify the concerns on the use of music, as well. Specifically, $22.3 \%$ were neutral to the statement that children with autism respond positively when sound and music activities are introduced in the classroom, 3.2\% disagreed and 1.1\% (1 respondent) strongly disagreed. Similarity, 37.2\% were neutral to the efficacy of using music to alleviate negative emotions, while $12.8 \%$ disagreed and $2.1 \%(2$ respondents) strongly disagreed. Finally, $24.5 \%$ were neutral to use of music as a medium to create a safe environment in the classroom.

Following the work of Latane and Nowak (1994) who state that people seem to take neutral attitudes about topics or items they do not deem important, the researchers grouped as positive the responses for which the participants indicated that they agree and strongly agree and as negative the responses for which the participants indicated that they strongly disagree, they disagree and they are neutral. The relationship between the positive (marked as 4-agree and 5-strongly agree on the Likert Scale) and negative responses (marked as 1-strongly disagree, 2-disagree, and 3-neutral on the Likert Scale) of the participants on all items related to the use of music as a tool to promote students with ASD emotional development is visually depicted in Table 3 and Figure 2.

Table 3. Grouped positive, neutral and negative responses on Part 2 of the Questionnaire

\begin{tabular}{|c|c|c|c|c|}
\hline \multirow[t]{2}{*}{ Category } & \multicolumn{2}{|c|}{$\begin{array}{l}\text { Positive } \\
\text { Responses }\end{array}$} & \multicolumn{2}{|c|}{$\begin{array}{l}\text { Negative } \\
\text { Responses }\end{array}$} \\
\hline & $\mathrm{N}$ & $\%$ & $\mathrm{~N}$ & $\%$ \\
\hline 1 Safe Environment & 71 & 75,5 & 23 & 24,5 \\
\hline 2 Creativity & 73 & 77,7 & 21 & 22,4 \\
\hline 3 Emotional state & 69 & 73,5 & 25 & 26,6 \\
\hline 4 Self Esteem & 61 & 64,9 & 33 & 35,1 \\
\hline 5 Emotional Outlet & 56 & 59,6 & 38 & 40,4 \\
\hline $\begin{array}{l}6 \text { Emotional } \\
\text { Management }\end{array}$ & 66 & 70,2 & 28 & 29,8 \\
\hline 7 Negative emotions & 45 & 47,9 & 49 & 52,1 \\
\hline
\end{tabular}


Figure 2. Grouped positive, neutral and negative responses on Emotional Development \& Music

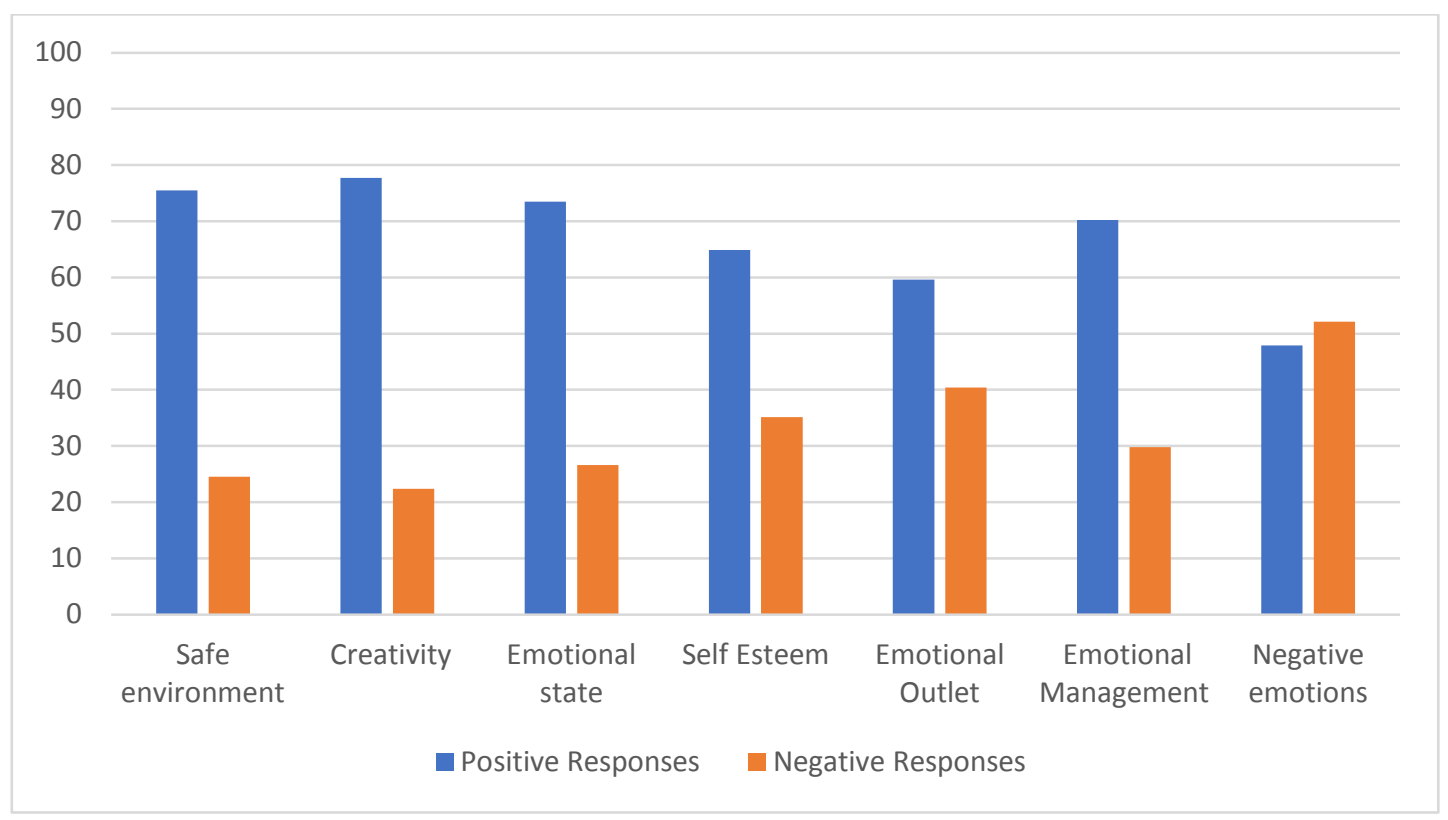

\section{Music as a Tool for Social Development and Communication}

The participants seemed to be positive on the use of music as a tool to promote young students' with ASD social development. In the questionnaire, participants ranked a variety of social development indicators in relation to the use of music ( 5 being strongly important and 1 not so important). In this section, $45.7 \%$ of the participants agreed with the statement that music is a highly important strategy to enhance socialization among young children with ASD and their peers. In addition, 47.9\% agreed that participation in music activities helps young students with ASD when following classroom rules and $48.9 \%$ agreed that music activities promote a classroom culture of acceptance and collaboration among all students in the group.

Music seems to be a tool for creating a sense of belonging for all students in the classrooms of the participants, as $27.7 \%$ highly agreed and $39.4 \%$ agreed with this statement. Also, 50\% of the respondents agreed that music activities can function as the medium to promote acceptance and community building within the classroom, while $40.4 \%$ of the participants agreed that music can promote self-expression and it is an emotional outlet for young children with ASD. Finally, 45.7\% of the participants agreed that vocalizations and the use of songs are effective strategies used by the teachers to promote language development and speech production for students with ASD.

Figure 3 illustrates the participants' responses on the use of music to enhance social development and communication of young children with ASD in their classrooms. 
Figure 3. Participants' responses on the effectiveness of music on social communication

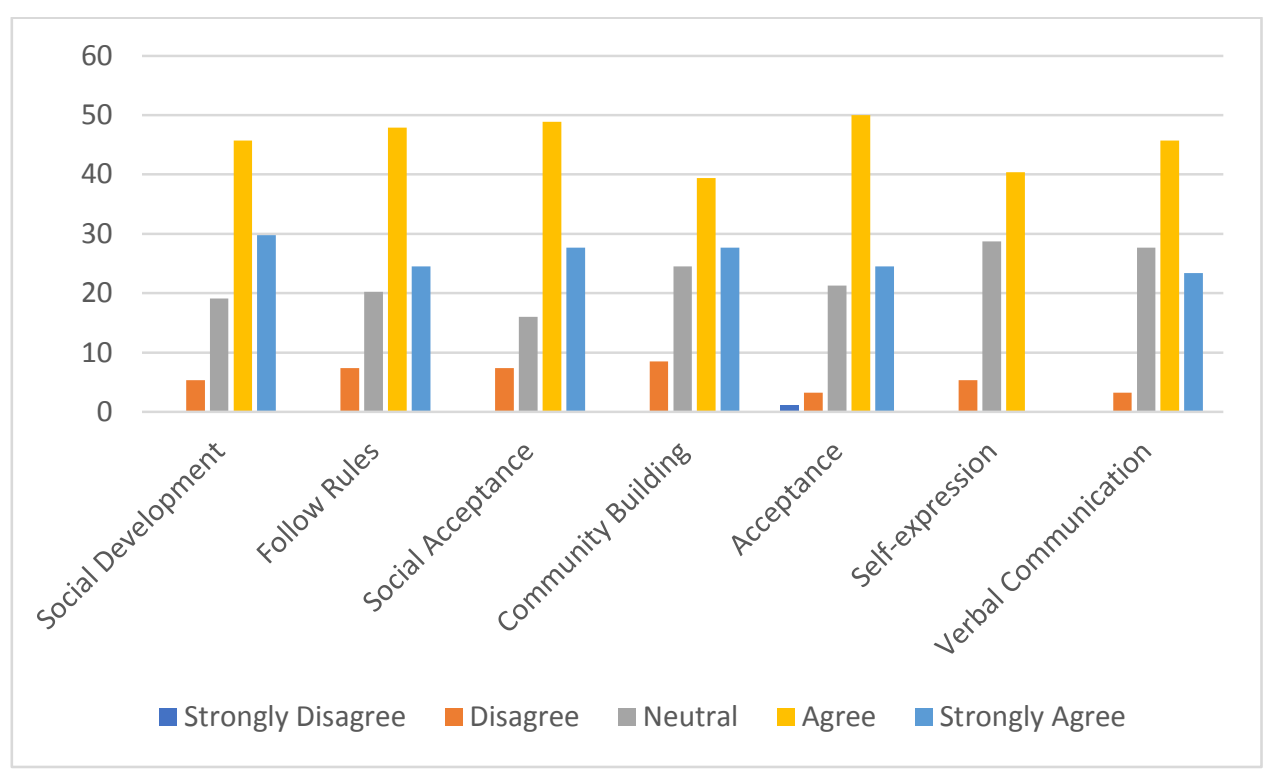

Last but not least, the respondents did not report positive connections between the use of music and setting rules and boundaries for their young students. For example, $7.4 \%$ of the participants disagreed with the statement that rules can be taught through music and that children can learn through improvisation how to express their positive and negative feelings, while $20.2 \%$ were neutral on this item. A grouped report of the positive (marked as 4-agree and 5-strongly agree on the Likert Scale) and negative responses (marked as 1-strongly disagree, 2-disagree, and 3-neutral on the Likert Scale) of the participants on the use of music as a tool to promote students' with ASD social development is visually depicted in Table 4 and Figure 4.

Table 4. Grouped positive, neutral and negative responses on Part 3 of the Questionnaire

\begin{tabular}{lccccc}
\hline \multirow{2}{*}{ Category } & \multicolumn{2}{l}{ Positive } & \multicolumn{2}{l}{$\begin{array}{l}\text { Negative } \\
\text { Responses }\end{array}$} \\
\cline { 2 - 6 } & Responses & N & N & $\%$ \\
\hline 1 Social Development & 71 & 75,5 & 23 & 24,5 \\
2 Follow Rules & 68 & 72,4 & 26 & 27,6 \\
3 Social Acceptance & 72 & 76,6 & 22 & 23,4 \\
4 Community Building & 63 & 67,1 & 31 & 33,0 \\
5 Acceptance & 70 & 74,5 & 24 & 25,6 \\
6 Self-expression & 62 & 65,9 & 32 & 34,0 \\
7 Verbal Communication & 65 & 69,1 & 29 & 30,9 \\
\hline
\end{tabular}


Figure 4. Grouped positive, neutral and negative responses on Social Development \& Music

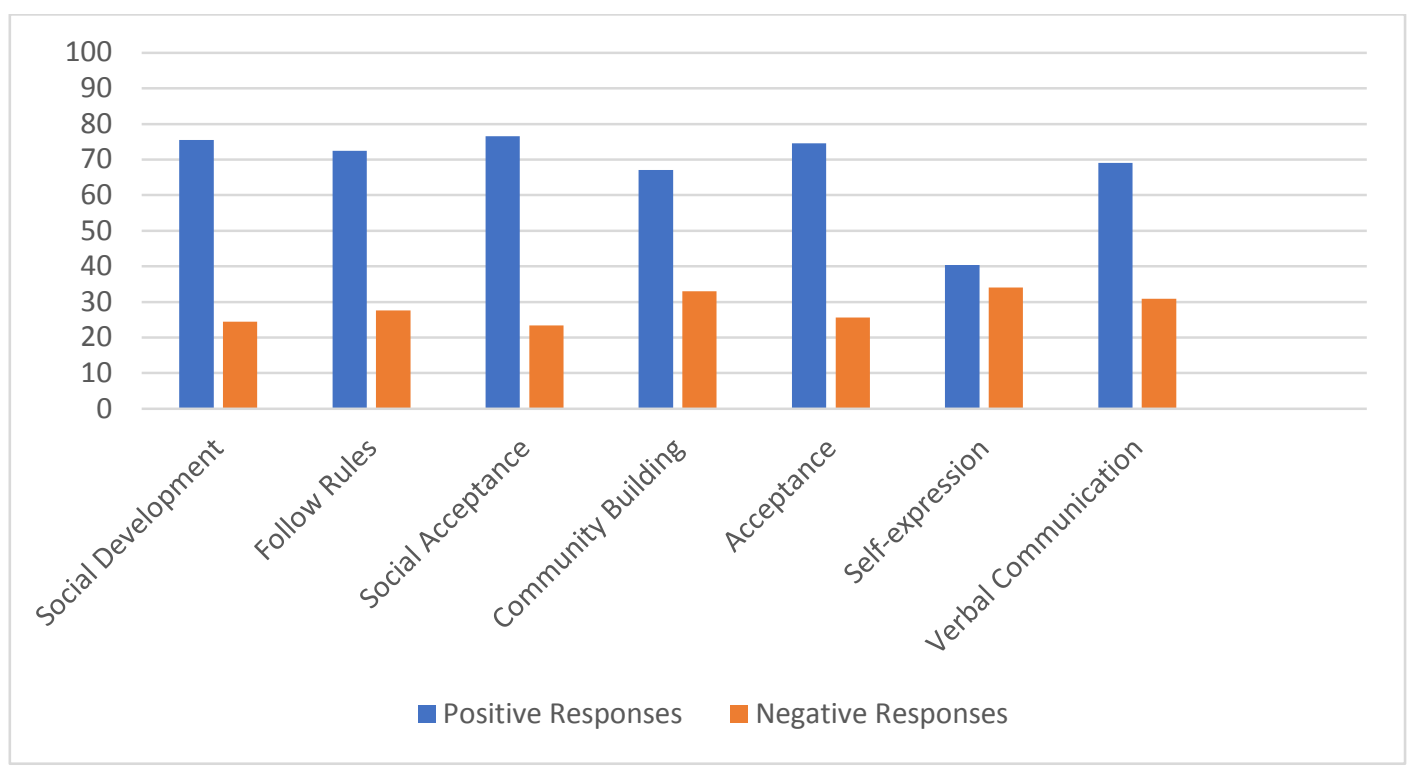

\section{Music strategies implemented in the classroom}

The third part of the questionnaire included open-ended questions on specific music strategies and activities that the participants implemented in their classrooms. The open-ended questions were answered by $75.5 \%$ of the respondents. In their responses, the participants outlined a variety of practices and music strategies they implement in their classrooms but they did not elaborate on the reasons for their choices, according to the second part of each question. Thus, the results include a frequency report (Figure 6) of the music practices that the participants reported using with their students, but there is no meaningful thematic analysis deriving from these results to be reported in the paper.

Overall, the respondents reported using music activities, including structured music projects, specific music education methods (e.g. Dalcroze, Kodaly, Orff) and music therapy strategies to motivate students interact with each other, express themselves and participate in the classroom routines. Specifically, in $79.8 \%$ of the responses obtained, the respondents mentioned that they choose a variety of age-appropriate music activities and modify them according to the needs and special traits of their students with ASD. 74.5\% of the participants reported that they don't use specific music approaches in their classroom, other than ageappropriate songs, while 25.5\% identified the Orff and Suzuki method as the ones that they implement during instructional time.

With regards to music exploration and improvisation, $37.2 \%$ of the participants shared that they mainly chose music activities with emphasis on sound explorations and listening skills. 16\% of the participants noted that they prefer music and movement activities for their students and 14.9\% of the participants identified songs as their choice because songs provide an enjoyable context for teaching academic skills to all students. Finally, only $7.4 \%$ of the participants stated that improvisation through musical instruments and voice is part of their curriculum. Figure 5 shows the music practices that the participants reported using with their students 
Figure 5. Music Strategies in the Classroom

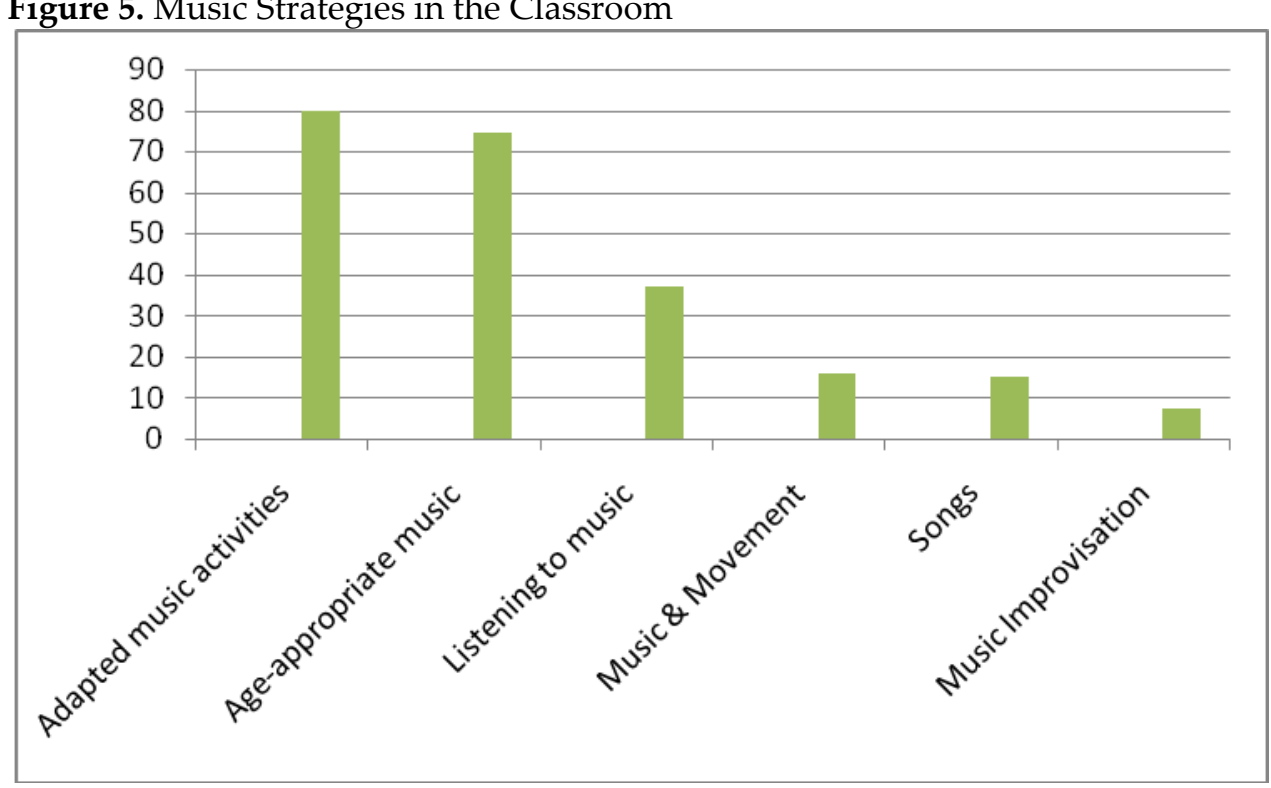

Figure 6 is a graphic depiction of the participants' responses on the use of various musical strategies to enhance academic and social development of all children in their classrooms, including those with ASD. In this part, the participants were asked to rank (following the 1-5 scale) the music activities they may use in the classroom. It is important to note that the participants ranked how often it is possible that they use the aforementioned strategies but they did not have to describe in detail how they implement these strategies in the classroom.

Figure 6. Use of Music Strategies

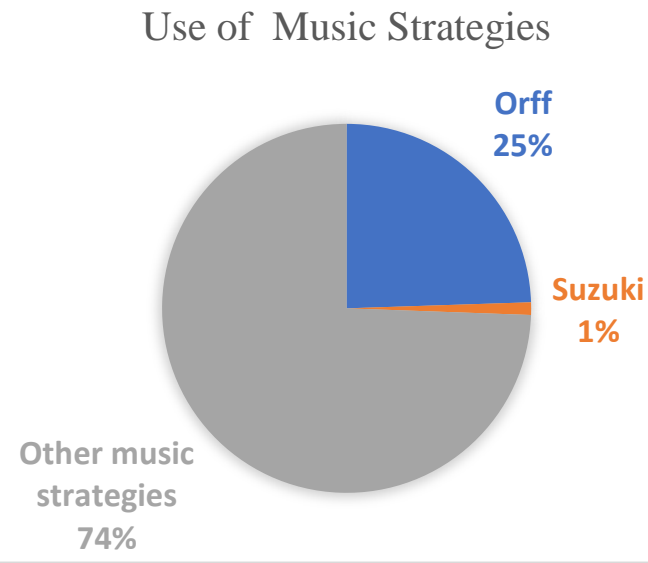

\section{RESULT, DISCUSSION, AND SUGGESTIONS}

The current study shows that early childhood educators hold positive views on the use of music as an instructional strategy in their classrooms. Participants in this study identified music as a viable tool that may support the academic and social growth of their students with ASD. Through their responses, it was evident 
that music activities may help students interact in an age-appropriate manner with their peers, establish relationships among students with ASD and their typical peers, promote self-expression, and offer opportunities for creativity and communication. Music strategies were, also, identified as a way to set clear expectations about the school's routines (for example, the use of songs to signal the beginning and the end of an activity), follow the classroom rules, and participate in classroom activities. Although, young children with ASD may have challenges in self-expression and sharing common interests with others (Baron-Cohen, 2008), participants seemed to agree that music activities, when embedded in the classroom routines, offer opportunities to meet the needs of all students, including those with ASD.

These findings align with current research on the use of music as a developmentally appropriate teaching tool in early childhood settings. Allgood (2005) noted that music may be the medium to promote communication and positive interactions among children with ASD and others in their social environment. Other studies have identified certain musical characteristics, such as the melody and the rhythm of familiar melodies, as the common denominator in the process of making connections with others (Kim et al. 2008; Kern \& Aldridge, 2006; Simpson \& Keen, 2010). Overall, shared musical experiences seem to be a childappropriate, teaching tool to encourage participation in the classroom activities and interactions with peers and adults in the room.

However, the respondents did not seem to find music activities as helpful when it comes to expressing negative emotions, classroom management, and negative behaviors. Early childhood educators in this study reported concerns for students with autism who express discomfort with sounds and some music activities. Research on the use of music for children with ASD confirms these concerns (e.g. McLaren, 2005; Ozonoff, Rodgers \& Hendron, 2003). In response to these concerns, current research pinpoints to targeted interventions on sound sensitivity and gradual exposure to music may help children learn to react in effectively self-regulating ways (Stiegler \& Davis, 2010).

In addition, there seems to be a disconnection between the participants' reported beliefs on the benefits of using of music and the actual music strategies implemented in the classrooms for young children with ASD. Specifically, a large number of the participants reported that they did not have any formal music education, they lack knowledge and experience in implementing specific music strategies in their classrooms, and music activities were more often than not, reduced to listening to pre-recorded music and singing along with it.

The aforementioned disconnection between beliefs and practices may be a reflection of the need for more training and support on how to use music in a variety of situations for young children with autism. Literature on teacher preparation highlights the needs for experiential learning and well-structured practicum to assist teachers in implementing music in their classrooms (Economidou, 2013). Early childhood educators typically attend courses and training about specific music approaches (such as Suzuki, Orff, and Dalcroze) but they do not feel confident about their training and practicum experience when implementing music activities in the classroom (Economidou \& Telemachou, 2006; Telemachou, 2007). As such, the lack of formal music training and their limited knowledge on music strategies may put barriers on the intentional use of music during instructional time, especially when it comes to support students, with diverse learning profiles.

These findings pinpoint to the importance of educational and practical support on the use of music for early childhood educators to advance their skills and knowledge. Koutsoupidou (2010) highlights the need for provisions for appropriate teaching and learning environments, availability of musical instruments, and school based resources can facilitate the use of music in the classroom. That way, music activities will be effectively implemented to create a culture of learning and sharing through play, exploration, and experimentation- all, important characteristics of early childhood education.

Continuing professional education may, also, support the use of music as an instructional tool in the classroom for early childhood educators. There is need for advanced-training courses and workshops designed to bridge music knowledge with its practical applications in inclusive, early childhood settings. Although, this is a well-documented need for early childhood educators in Greek settings (i.e. Koutsoupidou, 2010; Economidou, 2013), future research may look into aspects of professional training (such 
as the implementation of active music making, familiarity with differentiated instructions through music) in relation to the diverse learning needs of young children in inclusive settings.

Finally, promoting collaborations among early childhood educators (ECE), music educators, and music therapists in Greek public schools is recommended for implementing specific music activities within early childhood settings. Because of the special learning and social characteristics of young children with ASD, early childhood educators in inclusive settings may further benefit from collaborations with music educators and music therapists, either in the role of mentor and/or as co-teachers in the classrooms. Such collaborations may be one way to promote awareness and possibly enhance educators' self-efficacy and intentionality when using music in their classrooms. Partnerships among professionals lead to the identification of effective identification of young children's with ASD needs and strengths. Also, it makes possible the implementation of targeted music activities and interventions, which are essential for improving young children's educational and social abilities.

Although the results of the study are encouraging regarding the understanding and knowledge of ECE when using music in their classrooms, the study has some limitations. First, the response rate of the participants led to a rather smaller sample, than initially expected. More studies with bigger samples are needed to identify the perspectives and knowledge of ECE on the use of music and their needs. Second, the participants self-evaluated their use of music in the classroom. Observations and interviews might shed more light on the actual everyday implementation of music activities and teachers' decision process when using music as an instructional tool. Third, opportunities to observe and review collaborations among early childhood educators and music educators and/or music therapists would allow for a deeper understanding on the conditions and opportunities for embedding music into the school's daily routines to promote socioemotional development of young children with ASD. Finally, the emotional health of young children is closely tied to the social and emotional characteristics of the environments in which they live. Hence, it would be quite interesting to seek the views of the parents about the children's emotional states and expressing emotions in a socially acceptable way.

\section{REFERENCES}

Allgood, N. (2005). Parent's perception of family-based group music therapy for children with autism spectrum disorders. Music Therapy Perspectives, 23(2), 92-99.

American Psychiatric Association. (2013). Diagnostic and statistical manual of mental disorders (5 $5^{\text {th }}$ ed.). Arlington, VA: American Psychiatric Publishing.

Anvari, S. H., Trainor, L. J., Woodside, J., \& Levy, B. A. (2002). Relations among musical skills, phonological processing, and early reading ability in preschool children. Journal of experimental child psychology, 83(2), 111-130.

Baron-Cohen, S. (2008). Theories of the autistic mind. The Psychologist, 21(2), 112-116.

Bransford, J. D., Brown, A. L., \& Cocking, R. R. (1999). How people learn: Brain, mind, experience, and school. Washington, DC: National Academy Press.

Campbell, P. S. (2010). Songs in their heads: music and its meaning in children's lives. Oxford: Oxford Univ. Press.

Chrysostomou, S., Papapanagiotou, X. \& Dogani, K. (2007). Future and current educators: preparation, attitudes and needs for teaching music. In P.Simeonides (Ed.), Music education in search of its cultural identity, Electronic Proceedings of the 5th Conference of Greece Society for Music Education GSME, 29 June-1 July 2007, Thessaloniki.

Duffy, B., \& Fuller, R. (2000). Role of music therapy in social skills development in children with moderate intellectual disability. Journal of Applied Research in Intellectual Disabilities, 13(2), 77-89.

Economidou - Stavrou, A. (2013). Fostering musical creativity in pre-service teacher education: Challenges and possibilities. International Journal of Music Education, 31(1), 35-52. 
Economidou-Stavrou, A., \& Telemachou, N. (2006). Preparing future generalist teachers to teach music in primary school: Feedback from practicing teachers in Cyprus. Proceedings of the 27th World Conference of the International Society for Music Education, Kuala Lumpur, Malaysia.

Finnigan, E., \& Starr, E. (2010). Increasing social responsiveness in a child with autism: A comparison of music and non-music interventions. Autism, 14(4), 321-348.

Fyssa, A. \& Vlachou, A. (2015). Assessment of quality for inclusive programs in Greek preschool classrooms. Journal of Early Intervention, 37 (3), 190-207.

Geretsegger, M., Elefant, C., Mössler, K. A., \& Gold, C. (2014). Music therapy for people with autism spectrum disorder. The Cochrane Library.

Gold, C., Wigram, T., \& Elefant, C. (2006). Music therapy for autistic spectrum disorder. Cochrane Database of Systematic Reviews, Issue 2.

Horn, E., \& Banerjee, R. (2009). Understanding curriculum modifications and embedded learning opportunities in the context of supporting all children's success. Language, Speech, and Hearing Services in Schools, 40(4), 406-415.

Hudson, P., \& Hudson, S. (2007). Examining preservice teachers' preparedness for teaching art. International Journal of Education and the Arts, 8(5).

Johnson, S. C. (2000). The recognition of mentalistic agents in infancy. Trends in Cognitive Sciences, 4(1), 22-28.

Kagan, J., Herschkowitz, N., \& Herschkowitz, E. C. (2005). Young mind in a growing brain. Lawrence Erlbaum Assoc Inc.

Kaplan, R. S., \& Steele, A. L. (2005). An analysis of music therapy program goals and outcomes for clients with diagnoses on the autism spectrum. Journal of music therapy, 42(1), 2-19.

Kern, P., \& Aldridge, D. (2006). Using embedded music therapy interventions to support outdoor play of young children with autism in an inclusive community-based child care program. Journal of Music Therapy, 43, 270-294.

Kim, J., Wigram, T. \& Gold, C. (2008). The effects of improvisational music therapy on joint attention behaviors in autistic children: A randomized controlled study. Journal of Autism and Developmental Disorders, 38, 1758-1766.

Koutsoupidou, T. (2010). Initial music training of generalist kindergarten teachers in Greece: What do they ask for and what do they receive? Arts education policy review, 111(2), 63-70.

Latane, B. \& Nowak, A., (1994). Attitudes as catastrophes: from dimensions to categories with increasing involvement. In Vallacher, R. R., \& Nowak, A. Dynamical systems in social psychology. San Diego, CA, US: Academic Press

Lim, H. A. (2010). Effect of "developmental speech and language training through music" on speech production in children with autism spectrum disorders. Journal of music therapy, 47(1), 2-26.

McDowell, C. (2010). An adaption tool kit for teaching music. Teaching Exceptional Children Plus, 6 (3), 1-18.

McLaren, S. (2005). Noise and at risk children in early childhood education centres. Early Childhood Folio, 9, 39-43.

McWilliam, R. A., \& Casey, A. M. (2008). Engagement of every child in the preschool classroom. Baltimore, MD: Paul H. Brookes Publishing Company.

Missall, K., \& Hojnoski, R. (2008). The critical nature of young children's emerging peer-related social competence for transition to school. Social competence of young children: Risk, disability, and intervention, 117-137.

Mundy, P., \& Neal, R. (2001). Neural plasticity, joint attention and autistic developmental pathology. International review of research in mental retardation, 23, 139-168. 
Ockelford, A. (2011a). Songs without words: Exploring how music can serve as a proxy language in social interaction with autistic children who have limited speech, and the potential impact on their wellbeing. In R. MacDonald, G. Kreutz, \& L. Mitchell (eds.), Music, health and wellbeing. Oxford: Oxford University Press.

Ockelford, A. (2012). Commentary: Special abilities, special needs. In McPherson, G. \& Welch, G. (Eds.), The Oxford Handbook of Music Education. Vol2. (pp.7-10). New York, Oxford University Press.

Ockelford, A., \& Matawa, C. (2010). Focus on music 2: Exploring the musical interests and abilities of blind and partially-sighted children with retinopathy of prematurity. London: Institute of Education.

Odom, S. L., McConnell, S. R., \& Brown, W. H. (2008). Social competence of young children: Conceptualization, assessment, and influences. In W. Brown, S.L. Odom \& S.R. McConnell (Eds.), Social competence of young children: Risk, disability and intervention (pp. 3-29). Baltimore: Bookes.

Ozonoff, S., Rogers, S. J., \& Hendren, R. L. (2003). Autism spectrum disorders: A research review for practitioners. Washington, D.C: American Psychiatric Pub.

Plomin, R., Owen, M. J., \& McGuffin, P. (1994). The genetic basis of complex human behaviors. Science, 264(5166), 1733-1739.

Powell, D. R., Burchinal, M. R., File, N., \& Kontos, S. (2008). An eco-behavioral analysis of children's engagement in urban public school preschool classrooms. Early Childhood Research Quarterly, 23(1), 108-123.

Ridley, S. M., McWilliam, R. A., \& Oates, C. S. (2000). Observing children at play: Using engagement to evaluate activities and the classroom environment. Children and Families, 14(3), 36-38.

Shonkoff, J. P., \& Phillips, D. (2000). From neurons to neighborhoods: The science of early childhood development: National Academies Press.

Simpson, K. \& Keen, D. (2011). Music interventions for children with autism: Narrative review of the literature. Journal of Autism and Developmental Disorders, 41(11), 1507-1514.

Simpson, K., \& Keen, D. (2010). Teaching young children with autism graphic symbols embedded within an interactive song. Journal of Developmental and Physical Disabilities, 20, 165-177.

Simpson, K., Keen, D., \& Lamb, J. (2013). The use of music to engage children with autism in a receptive labelling task. Research in Autism Spectrum Disorders, 7(12), 1489-1496.

Stephens, C. E. (2008). Spontaneous imitation by children with autism during a repetitive musical play routine. Autism, 12, 645-671.

Stern, D. N. (1985). The Interpersonal world of the infant: a view from psychoanalysis and developmental psychology. London: Karnac Books.

Stiegler, L. N., \& Davis, R. (2010). Understanding sound sensitivity in individuals with autism spectrum disorders. Focus on Autism and Other Developmental Disabilities, 25(2), 67-75.

Tarrant, M., North, A. C., \& Hargreaves, D. J. (2000). English and American adolescents' reasons for listening to music. Psychology of Music, 28(2), 166-173.

Telemachou, N. (2007). Primary school student teachers' self efficacy beliefs for teaching music: a dialogic and interactive trajectory. Unpublished doctoral dissertation, University of Exeter, UK.

Vaiouli, P., \& Friesen, A. (2016). The magic of music: Engaging young children with autism spectrum disorders in early literacy activities with their peers. Childhood Education, 92(2), 126-133.

Vaiouli, P., \& Ogle, L. (2015). Music strategies to promote engagement and academic growth of young children with ASD in the inclusive classroom. Young Exceptional Children, 18(2), 19-28.

Vaiouli, P., Grimmet, K., \& Ruich, L. J. (2015). "Bill is now singing": Joint engagement and the emergence of social communication of three young children with autism. Autism, 19(1), 73-83. 
Wan, C. Y., Demaine, K., Zipse, L., Norton, A., \& Schlaug, G. (2010). From music making to speaking: engaging the mirror neuron system in autism. Brain research bulletin, 82(3), 161-168.

Welch, G., \& McPherson, G. (2012). Introduction and commentary: Music education and the role of music in people's lives. In McPherson, G. \& Welch, G. (Eds.) The Oxford Handbook of Music Education. Vol1. (pp. 5-20). New York, Oxford University Press

Whipple, J. (2004). Music in intervention for children and adolescents with autism: A meta-analysis. Journal of music therapy, 41(2), 90-106.

Appendix A

A. Demographics

\section{Questionnaire}

Question 1 Sex (Answer, putting $\mathbf{X}$ in the corresponding box)

$$
\text { Male }
$$

Female

Question 2 Age (Answer, putting $\mathbf{X}$ in the corresponding box)

$22-32$

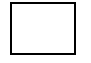

$32-42$

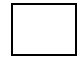

$42-55$

Question 3 Type of school

$$
\text { Special General }
$$

Question 4 Specialty (Answer, putting $X$ in the corresponding box) Early Childhood Educator with formal music education Early Childhood Educator (Answer, putting $\mathbf{X}$ in the corresponding box)

Question 5 Years of experience in the field of Special Education (Write a number in the box for the corresponding months or years)

\section{B. Emotional Development}

Please, indicate your level of agreement to the following statements.

(Answer, circling the corresponding number. In Likert-Scale, the responses ranged from 1-5, 1=strongly disagree and $5=$ strongly agree.)

Question 6 Music can create a secure, predictable and stable communication framework.

1

2

3

4

5

Question 7 Active participation to musical activities gives the child with autism a sense of security to express herself freely.
1
2
3
4
5

Question 8 Improvisation can contribute to the creation of a musical repertoire of communication. 
Question 9 The musical behavior of children with autism reflects their emotional state.

2

3

4

5

Question 10 Musical features, such as intensity or rhythm, can show the positive or negative feelings of children with autism.
1
2
3
4
5

Question 11 Musical improvisation can teach the child with autism that all feelings, positive and negative, are acceptable.
1
2
3
4
5

Question 12 The participation of children with autism in organized musical activities gives the opportunity to externalize emotional anxiety.

1

2

3

4

5

Question 13 The participation of the children with autism in organized musical activities provides the opportunity for tension-release experiences.

$\begin{array}{lllll}1 & 2 & 3 & 4 & 5\end{array}$

Question 14 The participation of children with autism in organized musical activities gives the opportunity to externalize the oppressed emotions.

1
2
3

4

5

Question 15 Children with autism respond positively when participating in music (i.e. listening to music, making music with others).
1
2
3
4
5

Question 16 Integrating music into the curriculum can promote children's with autism self-esteem

$\begin{array}{lllll}1 & 2 & 3 & 4 & 5\end{array}$

Question 17 The use of voice during an improvisation promotes language development for children with autism.

1

2

3

4

5

Question 18 Children with autism have difficulty recognizing and managing feelings. Music can be the means of expressing the right feeling.
1
2
3
4
5

\section{Socialization}

Question 19 Music can be used as a tool for developing social relationships for children with autism.
1
2
3
4
5

Question 20 Children with autism can co-ordinate and control their social interactions using music. 
Archontopoulou,A. \& Vaiouli,P. (2020).Music and social skills for young children with autism: A survey of early childhood educators. International Journal of Educational Research Review,5(3),190-207.

$\begin{array}{lllll}1 & 2 & 3 & 5\end{array}$

Question 21 Music can enhance teaching rules and routines for children with autism.

$\begin{array}{lllll}1 & 2 & 3 & 5\end{array}$

Question 22 Music can support connectedness with the group for children with autism.

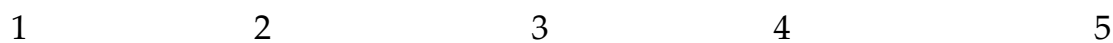

Question 23 Participation in shared experiences (i.e. singing together) promotes a sense of belonging in the group.
1
2
3
4
5

Question 24 Participation in shared experiences (i.e. singing together) promotes empathy.

$\begin{array}{lllll}1 & 2 & 3 & 4 & 5\end{array}$

Question 25 Participation in shared experiences (i.e. singing together) promotes solidarity and the sense of belonging.

$\begin{array}{lllll}1 & 2 & 3 & 4 & 5\end{array}$

Question 26 Music therapy influences the way the child with autism reacts to others.

1

2

3

4

5

D. Music activities

Question 27 Are your musical activities based on widespread practices?

No Yes

If so, which ones? (Report briefly)

Question 28 Are your musical activities shaped according to the needs of the children with autism?

No Yes

Question 29 Describe the music practices you apply in the classroom. (Report briefly)

Question 30 Are they effective? How would you change them to meet your students' needs? (Report briefly) 